\title{
Iron overload is rare in patients homozygous for the H63D mutation
}

\author{
Melissa Kelley MD, Nikhil Joshi MD, Yagang Xie MD, Mark Borgaonkar MD MSc
}

\begin{abstract}
M Kelley, N Joshi, Y Xie, M Borgaonkar. Iron overload is rare in patients homozygous for the H63D mutation. Can J Gastroenterol Hepatol 2014;28(4):198-202.
\end{abstract}

BACKGROUND: Previous research has suggested that the H63D HFE mutation is associated with elevated iron indexes. However, the true penetrance of this mutation remains unclear.

OBJECTIVE: To assess the proportion of H63D homozygotes with laboratory abnormalities consistent with iron overload.

METHODS: The present study was a retrospective analysis of all individuals referred for HFE genotyping in Newfoundland and Labrador between 1999 and 2009, who were found to be homozygous for the H63D mutation. Using electronic health records, results of ferritin, transferrin saturation, aspartate aminotransferase and alanine aminotransferase testing performed closest to the time of genetic testing were recorded for each patient. Iron overload was classified using previously published definitions from the HealthIron study. SPSS version 17.0 (IBM Corporation, USA) was used for descriptive statistics and to compare means using one-way ANOVA.

RESULTS: Between 1999 and 2009, 170 individuals tested positive for H63D/H63D. At the time of genotyping, 28.8\% had an elevated mean $( \pm$ SD) ferritin level of $501 \pm 829 \mu \mathrm{g} / \mathrm{L}$ and $15.9 \%$ had an elevated transferrin saturation of $0.45 \pm 0.18$. At genotyping, 94 individuals had sufficient data available to classify iron overload status. Only three (3.2\%) had documented iron overload while the majority $(85.1 \%)$ had no evidence of iron overload. Sixty individuals had follow-up data available and, of these, only four $(6.7 \%)$ had documented iron overload, while $45(75.0 \%)$ had no evidence of iron overload. Only one individual had evidence of iron overload-related disease at genotyping and at follow-up.

CONCLUSIONS: H63D homozygosity was associated with an elevated mean ferritin level, but only $6.7 \%$ had documented iron overload at follow-up. The penetrance of the H63D mutation appeared to be low.

\section{Key Words: Ferritin; Hemochromatosis; HFE}

$\mathrm{H}$ ereditary hemochromatosis $(\mathrm{HH})$ is one of the most common inherited conditions affecting individuals of Northern European descent. HH is inherited in an autosomal recessive pattern and is characterized by increased iron absorption and tissue deposition (1). This may cause organ damage including cirrhosis, diabetes, cardiomyopathy, arthropathy and impotence. However, the majority of patients are asymptomatic at the time of diagnosis (1).

In 1996, Feder et al (2) identified the candidate gene for HH (subsequently designated HFE), which encoded a major histocompatability complex class 1-like molecule that was involved in iron uptake. The two most common mutations are $\mathrm{C} 282 \mathrm{Y}$ and H63D. The $\mathrm{C} 282 \mathrm{Y}$ is a missense mutation, with a cysteine-to-tyrosine substitution at amino acid position 282. The $\mathrm{C} 282 \mathrm{Y}$ mutation has been the most strongly implicated in the development of hemochromatosis. The H63D HFE mutation is a histidine-to-aspartic acid substitution at amino acid position 63. It has also been associated with hemochromatosis, but

\section{La surcharge en fer est rare chez les patients homozygotes à la mutation H63D}

HISTORIQUE : D'après des recherches passées, la mutation H63D HFE s'associe à des indices de fer élevés. Cependant, on n'en connaît pas la véritable pénétration.

OBJECTIF : Évaluer la proportion d'homozygotes H63D ayant des anomalies de laboratoire compatibles avec une surcharge en fer.

MÉTHODOLOGIE : La présente étude était une analyse rétrospective de toutes les personnes aiguillées pour le génotypage du HFE à TerreNeuve-et-Labrador entre 1999 et 2009, diagnostiquées comme homozygotes à la mutation H63D. Au moyen des dossiers de santé électroniques, les chercheurs ont compilé pour chaque patient les résultats des tests de ferritine, de saturation de la transferrine, d'aspartate aminotransférase et d'alanine aminotransférase effectués le plus près du moment du test génétique. Ils ont classé la surcharge en fer d'après les définitions déjà publiées dans l'étude HealthIron et utilisé le logiciel SPSS version 17.0 (IBM Corporation, États-Unis) pour compiler les statistiques descriptives et comparer les moyennes à l'aide de l'analyse de variance unidirectionnelle.

RÉSULTATS : Entre 1999 et 2009, 170 personnes ont obtenu des résultats positifs à la mutation $\mathrm{H} 63 \mathrm{D} / \mathrm{H} 63 \mathrm{D}$. Au moment du génotypage, 28,8 \% présentaient un taux de ferritine moyen ( \pm ÉT) élevé de $501 \pm 829 \mu \mathrm{g} / \mathrm{L}$ et $15,9 \%$, une saturation de la transferrine élevée de $0,45 \pm 0,18$. Au génotypage, les chercheurs possédaient assez de données pour classer le statut de surcharge en fer de 94 personnes. Seulement trois $(3,2 \%)$ présentaient une surcharge en fer vérifiée, tandis que la majorité $(85,1 \%)$ n'en présentait aucune manifestation. Soixante personnes avaient des données de suivi, et de ce nombre, seulement quatre $(6,7 \%)$ avaient une surcharge en fer vérifiée, tandis que 45 (75,0 \%) n'en présentaient aucune manifestation. Une seule personne avait des manifestations de maladie liée à une surcharge en fer à la fois au génotypage et au suivi. CONCLUSIONS : L'homozygotie H63D s'associait à un taux de ferritine moyen élevé, mais seulement $6,7 \%$ présentaient une surcharge en fer vérifiée au suivi. La pénétration de la mutation H63D semblait faible.

to a lesser extent than C282Y; the overall clinical significance of this mutation remains unclear. Some postulate that it plays a role in the development of the disease but that the penetrance tends to be low (3-8). Some studies have suggested that the H63D mutation is simply a polymorphism and may not be of clinical significance when present without any other mutations (9-11).

If $\mathrm{HH}$ is recognized early in its course, phlebotomy therapy can prevent the complications of iron deposition. This has led to some discussion regarding screening individuals for $\mathrm{HH}$ because the condition meets many of the WHO criteria for population screening (1). However, the penetrance of the disease is variable and some studies have shown that even individuals homozygous for the C282Y mutation may not develop clinically overt disease (12).

In a previous study, we found that H63D homozygotes had a significantly higher transferrin saturation than the wild-type genotype. We also showed that the degree of transferrin saturation elevation was

Faculty of Medicine, Memorial University, St John's, Newfoundland and Labrador

Correspondence: Dr Melissa Kelley, Toronto Western Hospital, 399 Bathurst Street, 6B Fell Pavilion, Toronto, Ontario M5T 2 S8.

E-mail melkelley08@gmail.com

Received for publication November 7, 2013. Accepted January 25, 2014 
TABLE 1

Iron overload categories*

\begin{tabular}{|c|c|}
\hline Variable & Clinical finding or laboratory measure \\
\hline \multirow[t]{4}{*}{ Documented iron overload } & At least one of the following: \\
\hline & 1. Increased iron content shown by hepatic iron staining 3 or 4 , iron concentration $>90 \mu \mathrm{mol} / \mathrm{g}$ or hepatic iron index $>1.9$, \\
\hline & OR \\
\hline & 2. Serum ferritin $>1000 \mu \mathrm{g} / \mathrm{L}$ at baseline with documented therapeutic venesection \\
\hline \multirow[t]{3}{*}{ Provisional iron overload } & 1. Elevated serum ferritin ( $>300 \mu \mathrm{g} / \mathrm{L}$ for men and postmenopausal women, $>200 \mu \mathrm{g} / \mathrm{L}$ for premenopausal women), AND \\
\hline & 2. Elevated transferrin saturation ( $>55 \%$ for men and $>45 \%$ for women). \\
\hline & Either normal or elevated serum ferritin with normal transferrin saturation \\
\hline \multirow[t]{6}{*}{ Iron overload-related disease } & Meet the criteria for documented iron overload plus at least one of the following: \\
\hline & 1. Hepatocellular carcinoma \\
\hline & 2. Cirrhosis or fibrosis on liver biopsy \\
\hline & 3. Tenderness or effusion of the second and third metocarpophalangeal joints \\
\hline & 4. Elevated aspartate aminotransferase (>45 IU/L) or alanine aminotransferase (>40 IU/L) \\
\hline & 5. Diagnosis by a physician owing to symptoms associated with hereditary hemochromatosis \\
\hline
\end{tabular}

${ }^{*}$ Data adapted from the Heathlron study (14)

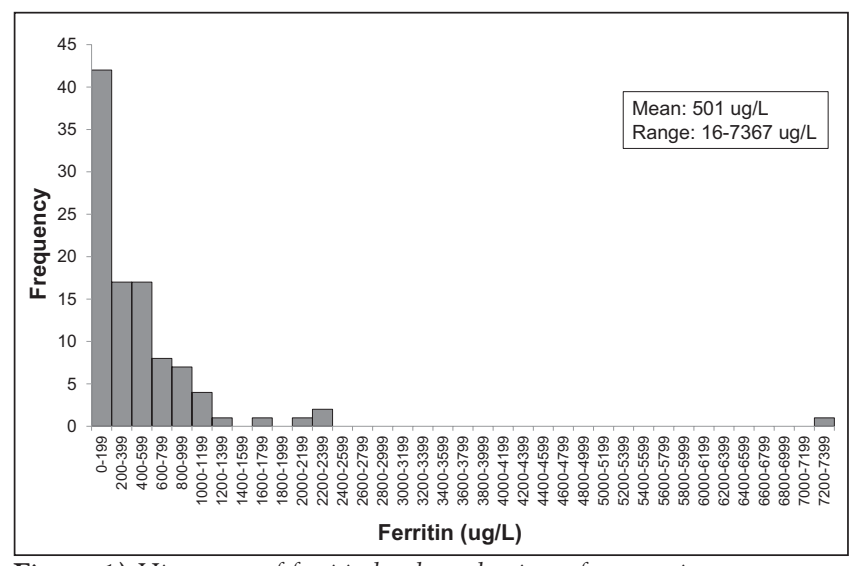

Figure 1) Histogram of ferritin levels at the time of genotyping

comparable with C282Y homozygotes and compound heterozygotes. However, the clinical significance of these results could not be determined (13).

The purpose of the present study was to determine the penetrance of H63D homozygosity in a referred population in Newfoundland and Labrador by following a cohort of H63D homozygotes for evidence of iron overload.

\section{METHODS}

The present study was approved by the Research Ethics Board of Memorial University of Newfoundland (St Johns, Newfoundland and Labrador) before commencement. Subjects were from Newfoundland and Labrador, an island comprised predominantly of Caucasians of Irish and English descent. The present study was a retrospective analysis of all individuals referred for HFE genotyping in Newfoundland and Labrador from 1999 to 2009, who were identified to be homozygous for the HFE H63D mutation. The indication for genotyping was not stated on the requisition. There is only one laboratory in the province that performs genotyping for $\mathrm{HH}$, enabling the authors to identify every individual who tested positive for H63D homozygosity. During the study period, only the C282Y and H63D mutations were assessed.

Using electronic health records, age, sex, ferritin levels, serum iron, transferrin saturation, aspartate aminotransferase (AST) and alanine aminotransferase (ALT) levels closest to the time of genetic testing were recorded. To avoid including information from partially treated individuals, only bloodwork data obtained within six months of the genetic test were recorded. Measurement of transferrin saturation was not performed specifically in the fasting state. Follow-up laboratory values were recorded annually up to February 2011. Ferritin $>335 \mu \mathrm{g} / \mathrm{L}$, AST and ALT $>37$ IU/L and transferrin saturation $>0.55$ were considered to be abnormally elevated. Liver biopsy results and treatment

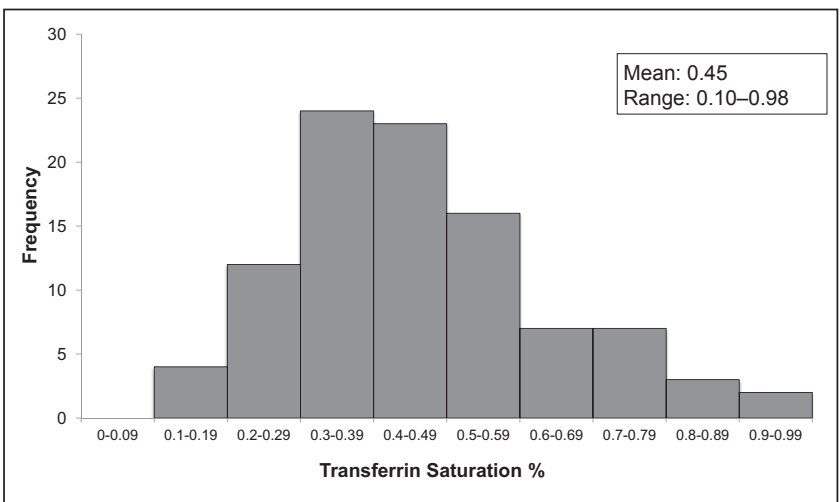

Figure 2) Histogram of transferrin saturation levels at the time of genotyping

with phlebotomy were also documented if recorded in the electronic health record. Iron overload was classified using previously published definitions from the HealthIron study (14) (Table 1). Briefly, this system classifies patients into one of four iron overload categories, ranging from no evidence of iron overload to iron overload-related disease.

The data were summarized using descriptive statistics. Incidence and prevalence of iron-overload were calculated using the number of patients with complete data as the denominator. SPSS version 17.0 (IBM Corporation, USA) was used for descriptive statistics and to compare means using Student's $t$ test or one-way ANOVA; $\mathrm{P} \leq 0.05$ was considered to be statistically significant.

\section{RESULTS}

A total of 4138 individuals underwent HFE genotyping in Newfoundland and Labrador between 1999 and January 2009. There were 366 (8.8\%) C282Y homozygotes, 170 (4.1\%) H63D homozygotes, 758 (18.3\%) C282Y heterozygotes, 858 (20.7\%) H63D heterozygotes, 267 (6.4\%) compound heterozygotes and 1719 (41.5\%) wild type. Of the $170 \mathrm{H63D}$ homozygotes, $116(68.2 \%)$ were male and 54 (31.8\%) were female. The mean age at the time of genotyping was 48.9 years. At the time of genotyping, $28.8 \%$ had an elevated ferritin level and $15.9 \%$ had an elevated transferrin saturation. The mean ferritin level was $501 \mu \mathrm{g} / \mathrm{L}$ (range $16 \mu \mathrm{g} / \mathrm{L}$ to $7367 \mu \mathrm{g} / \mathrm{L}$ ) (Figure 1 ) and the mean transferrin saturation was 0.45 (range 0.10 to 0.98) (Figure 2). The mean AST level was $56 \mathrm{IU} / \mathrm{L}$, ALT $72 \mathrm{IU} / \mathrm{L}$, bilirubin $22.6 \mu \mathrm{mol} / \mathrm{L}$, international normalized ratio 1.5 and albumin $40.7 \mathrm{~g} / \mathrm{L}$ (Table 2 ).

The mean follow-up duration was $4.2 \pm 2.6$ years. There was no significant increase in the mean ferritin level over time.

At the time of genotyping, the records of 94 individuals contained sufficient data to determine iron overload status (Figure 3). The 


\section{TABLE 2}

\section{Baseline characteristics}

\begin{tabular}{lc}
\hline Characteristic & Mean (range) \\
\hline Age at genotyping, years & $48.9(17-77)$ \\
Ferritin, $\mu$ g/L & $501(16-7367)$ \\
Transferrin saturation & $0.45(0.10-0.98)$ \\
Aspartate aminotransferase, IU/L & $56.3(14-992)$ \\
Alanine aminotransferase, IU/L & $71.7(12-1190)$ \\
Bilirubin, $\mu \mathrm{mol} / \mathrm{L}$ & $22.6(3-223)$ \\
International normalized ratio & $1.5(0.87-10.0)$ \\
Albumin, g/L & $40.7(21-48)$ \\
\hline
\end{tabular}

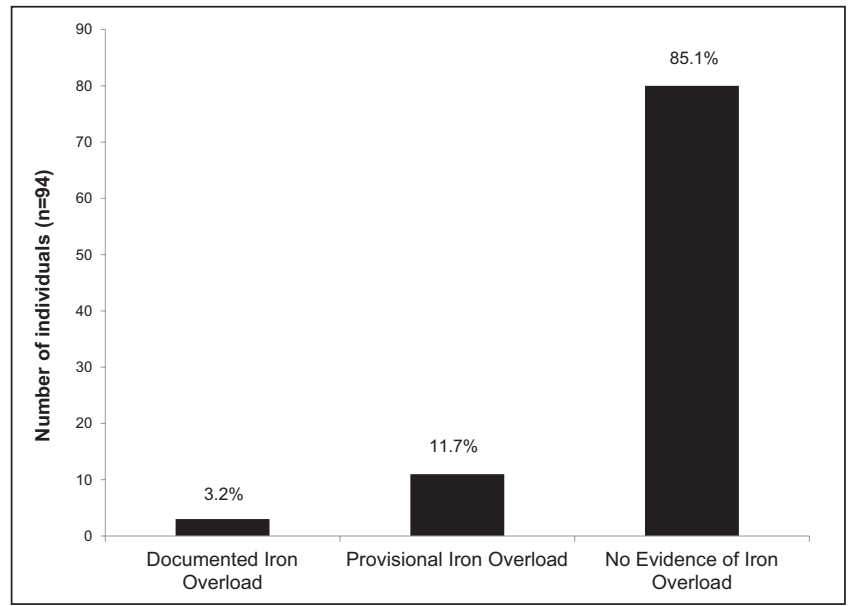

Figure 3) Iron overload status at time of genotyping

majority of H63D homozygotes (85.1\%) had no evidence of iron overload. Three (3.2\%) had documented iron overload, with one $(1.1 \%)$ meeting criteria for iron overload-related disease. Eleven (11.7\%) had provisional iron overload. Sixty individuals had follow-up data available and, of these, four (6.7\%) had documented iron overload. Only one $(1.7 \%)$ of these individuals met criteria for iron overload-related disease. Eleven (18.3\%) had provisional iron overload and 45 (75.0\%) had no evidence of iron overload (Figure 4).

Only one individual had iron overload-related disease, both at the time of genotyping and at follow-up. Clinical records noted excess alcohol consumption in that case. Two $(3.3 \%)$ individuals progressed from no evidence of iron overload to provisional iron overload. There were two individuals without sufficient data for a baseline classification of iron status who did meet criteria for some degree of iron overload during follow-up. One met the criteria for documented iron overload and one met the criteria for provisional iron overload.

Eight individuals underwent phlebotomy after genotyping. The details of the frequency and duration of phlebotomy were not available. None of the six individuals for whom follow-up data were available showed progression of iron overload.

\section{DISCUSSION}

The results of the present study suggest a low penetrance of H63D homozyosity. Although serum ferritin levels were elevated at baseline, there was no significant increase in mean ferritin level for the cohort over time. Only three individuals met the criteria for iron overload at the time of genotyping and four at follow-up. Within this group, only one individual met the criteria for iron overload-related disease. That patient was documented to have abused alcohol, such that one cannot be certain whether iron overload was the primary cause of his liver disease. The majority of the individuals in our study showed no evidence of iron overload ( $85.1 \%$ at baseline and $75.0 \%$ at follow-up). Only two individuals demonstrated any progression of their iron overload status during the study $(3.3 \%)$.

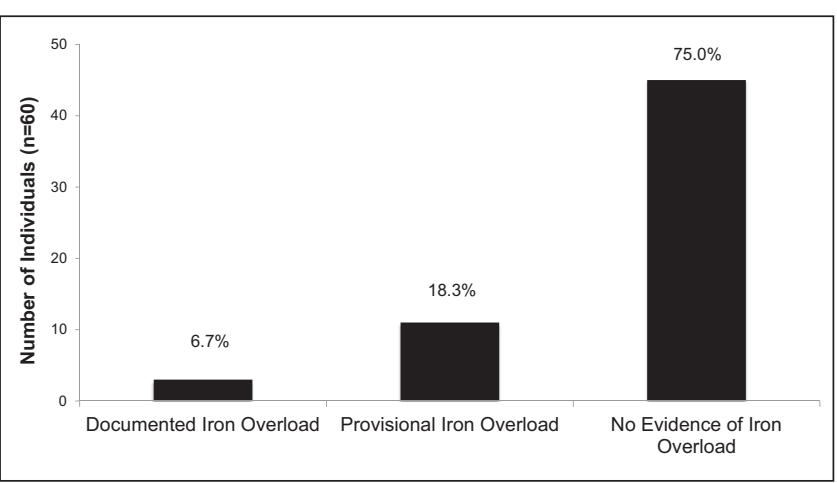

Figure 4) Iron overload status at follow-up

In a previous study involving this same population, we found that H63D homozygosity was associated with a significantly higher mean transferrin saturation when compared with the wild-type genotype $(0.44 \pm 0.18$ versus $0.34 \pm 0.17 ; \mathrm{P}<0.01)$. In that study, $42.0 \%$ of $\mathrm{H} 63 \mathrm{D}$ homozygotes had elevated ALT levels compared with $30.1 \%$ of $\mathrm{C} 282 \mathrm{Y}$ heterozygotes $(\mathrm{P}=0.04)(15)$.

The results of the present study are consistent with other studies that have found the H63D mutation to be associated with elevated iron levels $(3,7,9,10,13,16,17)$. Phatak et al (17) found that the H63D homozygotes had a significantly elevated mean transferrin saturation when compared with the wild-type genotype, but this was not above the upper limit of normal. Gochee et al (10) found that $15 \%$ of male H63D homozygotes and 12\% of male H63D heterozygotes had an elevated transferrin saturation compared with only $5 \%$ in the wild-type genotype $(\mathrm{P}<0.01)$. Samarasena et al $(13)$ conducted a study involving the Newfoundland and Labrador population and found that the H63D homozygotes had significantly elevated transferrin saturation compared with the wild-type genotype $(0.51 \pm 0.21$ versus $0.34 \pm 0.17 ; \mathrm{P}<0.01)$. They also had an elevated mean ferritin level $(920.3 \pm 1687.1 \mu \mathrm{g} / \mathrm{L})$ but it was not statistically significant compared with the other genotypes (13). The Hemochromatosis and Iron Overload Screening (HEIRS) study (18) also found elevated ferritin levels and transferrin saturation to be more common among compound heterozygotes and H63D homozygotes when compared with the wild type, although the mean values were within the normal range.

Although the H63D homozygous mutation has been associated with elevated iron indexes, it is unclear whether these individuals require phlebotomy or whether they will progress to develop clinically significant iron overload. Several studies have suggested that H63D homozygosity has a much lower penetrance than C282Y homozygosity and are at a lower risk for developing clinically significant iron overload $(4,11)$. Neghina et al (19) conducted a meta-analysis examining the association between the various HFE genotypes and iron overload. They found that in individuals with a clinical diagnosis of hemochromatosis, the C282Y homozygous genotype had a 100 times greater association with an elevated transferrin saturation (>55\%) and elevated serum iron and serum ferritin when compared with H63D homozygotes. In cases for which hemochromatosis was documented by an elevated hepatic iron index and/or mobilizable iron by quantitative phlebotomy, C282Y homozygosity was 100 times more strongly associated with iron overload than H63D homozygosity (19).

Other studies have shown the H63D mutation to be associated with clinically significant iron overload. One study found that three of 61 individuals with a phenotypic diagnosis of hemochromatosis were homozygous for the H63D mutation (5). These patients had either a hepatic iron index $>1.9$ or mobilizable iron stores of $>4 \mathrm{~g}$. A study by Brissot et al (20) determined the HFE genotypes of 217 patients with a phenotypic diagnosis of hemochromatosis. The majority (96.3\%) were homozygous for the $\mathrm{C} 282 \mathrm{Y}$ mutation. Four individuals were compound heterozygotes, one was homozygous for the H63D mutation and one was heterozygous for the H63D mutation. Although the C282Y 
mutation was most frequently associated with hemochromatosis, they did find that the H63D mutation occurred more frequently in the hemochromatosis population when compared with the control group. However, not all of these patients underwent liver biopsies and, in some, the phenotypic diagnosis was based solely on the elevated transferrin saturation.

Aguilar-Martinez et al (21) conducted a study involving a population referred for HFE genotyping and found a wide variety of phenotypes among the H63D homozygotes, ranging from normal to severe iron overload. Within this population, 24\% of H63D homozygotes had a hemochromatosis phenotype characterized by an elevated ferritin and transferrin saturation level plus either iron overload on liver biopsy or quantitative phlebotomy. This study suggests a significantly higher penetrance of the H63D mutation than what was shown in our population. This difference is likely due to the reason for genotyping. Aguilar-Martinez et al (21) included patients referred for testing with either a personal or family history of iron overload, including 12 individuals (24\% of the study population) previously diagnosed with hemochromatosis. Therefore, one would expect to find a more severe phenotype in this cohort. In our cohort, the reason for referral was not documented. Family history and elevated iron studies would have been the reason for referral in a proportion of our cohort. Some of the H63D homozygotes in our cohort had elevated transaminase levels, which likely was the reason for investigation in some patients. This heterogeneity in patients sent for genotyping is likely the reason why our cohort demonstrated a broader spectrum of iron overload severity than reported by Aguilar-Martinez et al (21).

Some have postulated that H63D homozygotes who develop clinically significant iron overload may have another unidentified contributing mutation. One study examined H63D homozygotes with significantly elevated transferrin saturation and serum ferritin levels for mutations affecting other iron regulatory genes (22). The investigators screened specifically for 18 known HFE, TFR2 and FPN1 mutations and had complete sequencing of the HAMP gene. They were unsuccessful in finding any mutations affecting these genes in the 45 H63D homozygotes.

Some authors have proposed that environmental factors play a role in the variable penetrance of the hemochromatosis mutations. Aranda et al (16) found that iron intake, alcohol intake, tobacco habit and male sex were all positively associated with elevated iron studies in all HFE genotypes containing $\mathrm{C} 282 \mathrm{Y}$ or $\mathrm{H} 63 \mathrm{D}$ and in S65C homozygotes. It has also been postulated that another process affecting the liver may actually be contributing to the increase in iron load. Bacon et al (11) measured the hepatic iron concentration of 132 patients with liver disease. Five of these were homozygous for H63D and there was no significant difference in the hepatic iron concentration or the hepatic index compared with the wild-type genotype. All five patients received a diagnosis of conditions other than hemochromatosis causing their liver disease (11).

The distribution of genotypes in our cohort does differ from a population-based study of hemochromatosis. The HEIRS study (18) examined a primary care population of 99,711 individuals. Within the Caucasian population of this group, $0.44 \%$ were homozygous for the C282Y mutation and 2.4\% were homozygous for the H63D mutation (18). The individuals in our study were referred by a health professional for HFE genotyping and were, therefore, not a true populationbased sample. The distribution of C282Y (8.8\%) and H63D homozygotes $(4.1 \%)$ present in our population was closer to the referred population studied by Aguilar-Martinez et al (21), which consisted of $18.4 \%$ C282Y homozygotes and 6.2\% H63D homozygotes.

The present study had several strengths. It was a large cohort followed for a long duration of time. Although the study was retrospective in nature, the data collection had been performed prospectively and provided us with ample data on a subset of patients.

There were, however, some limitations to the present study. It was retrospective in design and, therefore, was limited to the data that could be obtained from the electronic health records. Although we had the genotyping results from all individuals in the province, access to the primary health record (including clinical letters, additional laboratory tests, imaging and pathology results) was limited to only a subset of patients in the Eastern Health region. Consequently, only partial (or no) baseline and follow-up data were available for $69.4 \%$ of patients. We do not believe that the reason for incomplete data for some patients would bias the findings to affect the validity of our results. We were unable to obtain clinical information, such as alcohol consumption, for most individuals. However, for $30 \%$ of patients, we did have sufficient baseline and follow-up data to assess the natural history of H63D homozygosity. The duration of follow-up was limited by the health records themselves and when genotyping became available in this region. It is possible that if patients were followed for a longer duration, the results would be different.

The indication for genotyping was unknown for all patients in the cohort. Although we did find that the H63D homozygous mutation was associated with significantly elevated ferritin levels, it is possible that this was the reason the individuals underwent genotyping, which would bias these results.

\section{CONCLUSION}

The H63D homozygous mutation was associated with elevated iron indexes. Despite this, the incidence of documented iron overload was low (6.7\% at follow-up) and only one individual met the criteria for iron overload-related disease. The results of our study indicate that although the H63D mutation may be related to alterations in iron indexes and transaminase levels, the penetrance of this mutation in causing iron overload-related disease is low.

\section{REFERENCES}

1. Bacon BR. Hemochromatosis: Diagnosis and management. Gastroenterology 2001;120:718-25.

2. Feder J, Gnirke A, Thomas A, et al. A novel MHC class I-like gene is mutated in patients with hereditary haemochromatosis. Nat Genet 1996;13:399-408.

3. Matas M, Guix P, Castro JA, et al. Prevalence of HFE C282Y and $\mathrm{H} 63 \mathrm{D}$ in Jewish populations and clinical implications of H63D homozygosity. Clin Genet 2006;69:155-62.

4. Burke W, Imperatore G, McDonnell SM, Baron RC, Khoury MJ. Contribution of different HFE genotypes to iron overload disease: A pooled analysis. Gene Med 2000;2:271-7.

5. Sham RL, Ou CY, Cappuccio J, et al. Correlation between genotype and phenotype in hereditary hemochromatosis: Analysis of 61 cases. Blood Cells Mol Dis 1997;23:314-20.

6. Fairbanks VF, Brandhagen DJ, Thibodeau SN, Snow K, Wollan PC. H63D is an haemachromatosis associated allele. Gut 1998;43:441-4

7. Pedersen P, Milman N. Genetic screening for HFE hemochromatosis in 6,020 Danish men: Penetrance of C282Y, H63D, and S65C variants. Ann Hematol 2009;88:775-84.

8. Beutler E. The significance of the $187 \mathrm{G}(\mathrm{H} 63 \mathrm{D})$ mutation in hemochromatosis. Am J Hum Genet 1997;61:762-4.

9. Jackson HA, Carter K, Darke C, et al. HFE mutations, iron deficiency and overload in 10,500 blood donors. Br J Haematol 2001;114:474-84.

10. Gochee PA, Powell LW, Cullen DJ, et al. A population-based study of the biochemical and clinical expression of the H63D hemochromatosis mutation. Gastroenterology 2002;122:646-51.

11. Bacon BR, Olynyk JK, Brunt EM, Britton RS, Wolff RK. HFE genotypes in hemochromatosis and other liver diseases. Ann Intern Med 1999;130:1018-9.

12. Andersen RV, Tybjaerg-Hansen A, Appleyard M, Birgens H, Nordestgaard BG. Hemochromatosis mutations in the general population: Iron overload progression rate. Blood 2004;103:2914-9.

13. Samarasena J, Winsor W, Lush R, et al. Individuals homozygous for the H63D mutation have significantly elevated iron indexes. Dig Dis Sci 2006;51:803-7.

14. Allen KJ, Gurrin LC, Constantine CC, et al. Iron overload-related disease in HFE hereditary hemochromatosis. N Engl J Med 2008;358:221-30. 
15. Kelley M, Joshi N, Xie Y, Borgaonkar M. Hemochromatosis gene mutations in Newfoundland and their association with iron indices and transaminase levels. Gut 2010;59:A313.

16. Aranda N, Viteri FE, Montserrat C, Arija V. Effects of C282Y, H63D, and S65C HFE gene mutations, diet, and life-style factors on iron status in a general Mediterranean population from Tarragona, Spain. Ann Hematol 2010;89:767-73.

17. Phatak PD, Ryan DH, Cappuccio J, et al. Prevalence and penetrance of HFE mutations in 4865 unselected primary care patients. Blood Cells Mol Dis 2002;29:41-7.

18. Adams PC, Reboussin DM, Barton JC, et al. Hemochromatosis and iron-overload screening in a racially diverse population. N Engl J Med 2005;352:1769-78.
19. Neghina AM, Anghel A. Hemochromatosis genotypes and risk of iron overload - a meta-analysis. Ann Epidemiol 2011;21:1-14.

20. Brissot P, Moirand R, Jouanolle AM, et al. A genotypic study of 217 unrelated probands diagnosed as "genetic hemochromatosis" on "classical" phenotypic criteria. J Hepatol 1999;30:588-93.

21. Aguilar-Martinez P, Bismuth M, Picot MC, et al. Variable phenotypic presentation of iron overload in H63D homozygotes: Are genetic modifiers the cause? Gut 2001;48:836-42.

22. Diego C de, Opazo S, Murga MJ, Martínez-Castro P. H63D homozygotes with hyperferritinaemia: Is this genotype, the primary cause of iron overload? Eur J Haematol 2007;78:66-71. 


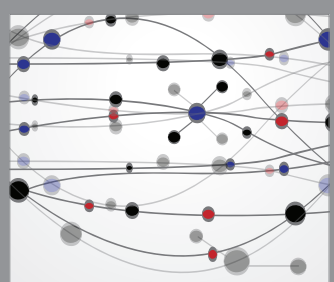

The Scientific World Journal
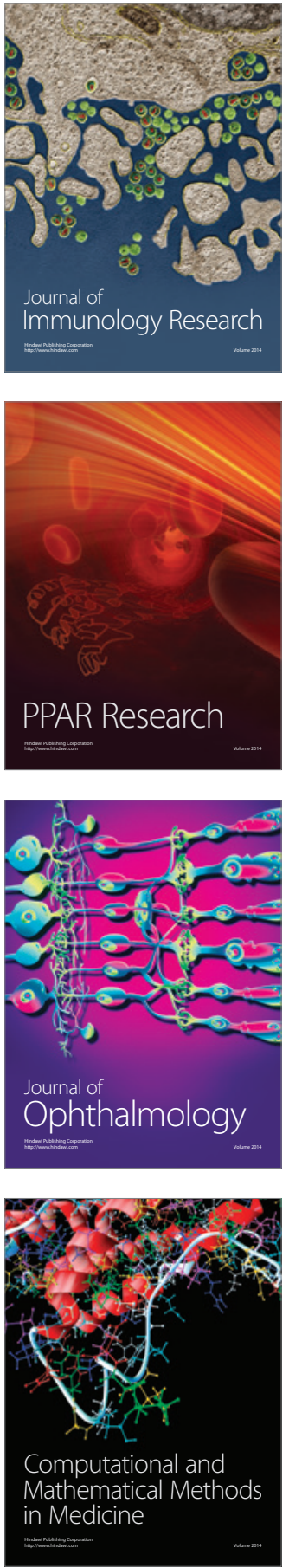

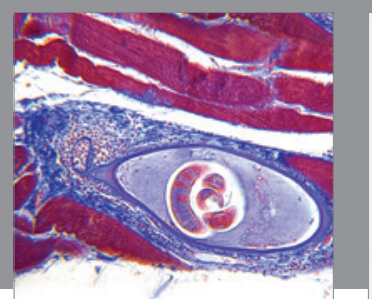

Gastroenterology Research and Practice

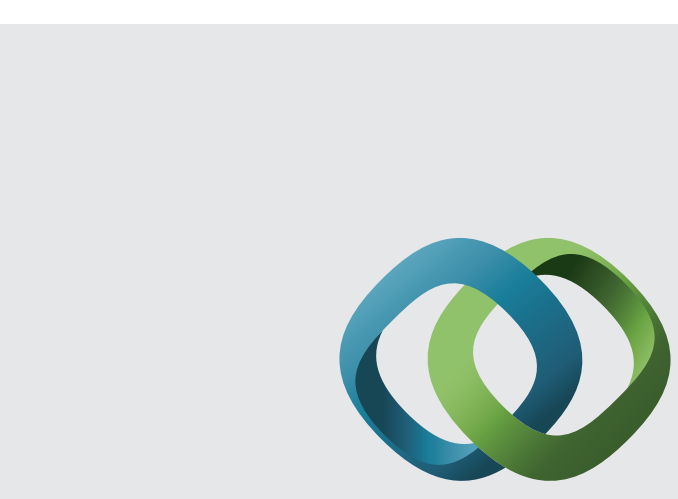

\section{Hindawi}

Submit your manuscripts at

http://www.hindawi.com
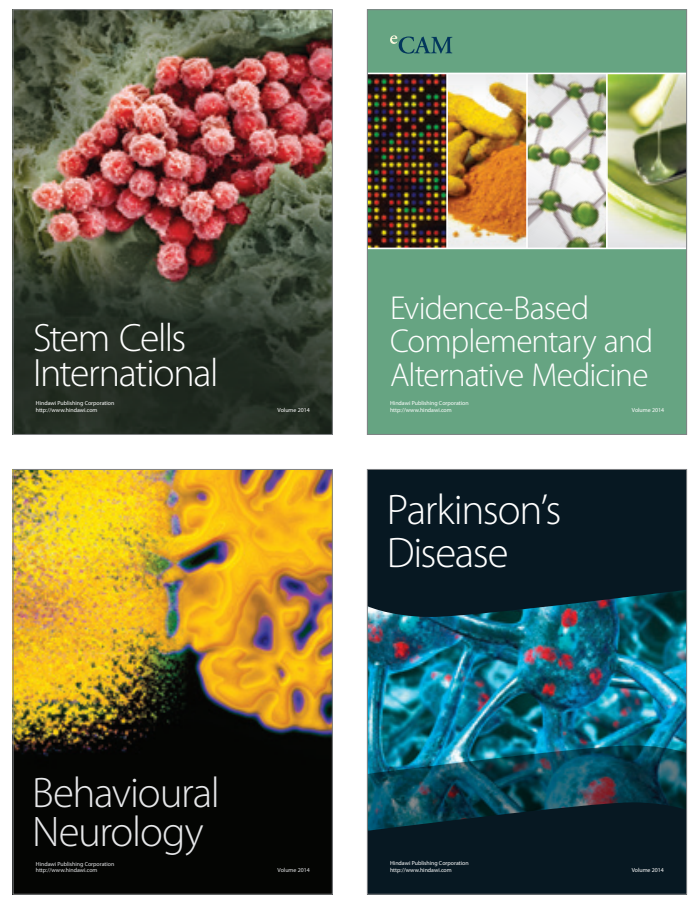
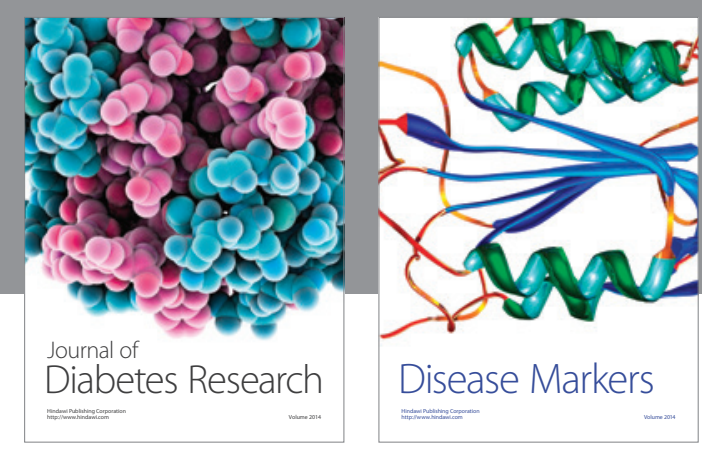

Disease Markers
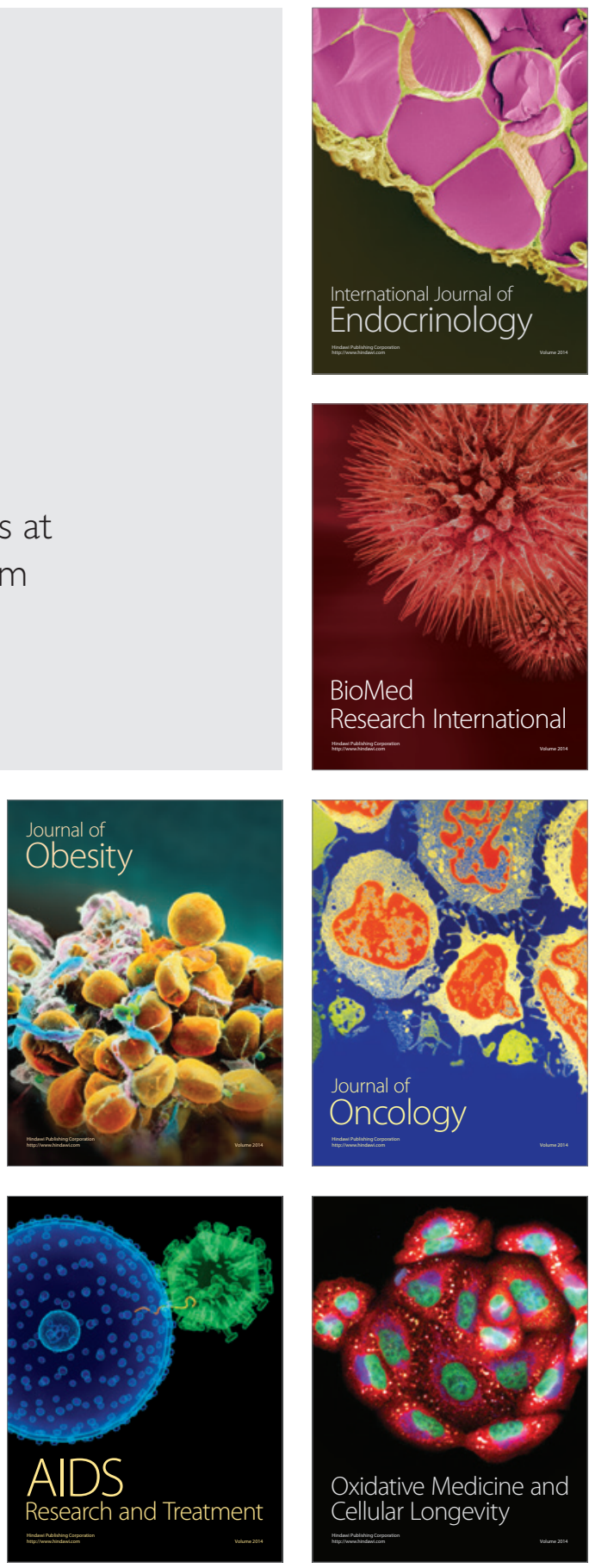